\title{
Dominant vs Nondominant Arm in Surgical Repair of Distal Biceps Tendon Rupture. A Case-Control Series of Isotonic Muscle Strength Evaluation
}

\author{
F. Calderazzi1', F. Addevico², C. Galavotti', A. Nosenzo', M. Menozzi', A. Garzia1, \\ C. Costantino ${ }^{3}$ \\ ${ }^{1}$ Department of Medicine and Surgery, Orthopaedic Clinic, Maggiore Hospital-University of Parma, Parma, Italy \\ 2 Department of Orthopaedic, ASST Metropolitan Hospital Niguarda, Milan, Italy \\ ${ }^{3}$ Department of Biomedical, Biotechnological and Traslational Sciences, Maggiore Hospital-University of Parma, \\ Parma, Italy
}

\section{CORRESPONDING AUTHOR: \\ Filippo Calderazzi \\ Department of Medicine and Surgery \\ Orthopaedic Clinic \\ Maggiore Hospital-University of Parma \\ via Gramsci 14 \\ 43126 Parma, Italy \\ E-mail: filippo.calderazzi@icloud.com}

DOI:

10.32098/mltj.02.2021.04

LEVEL OF EVIDENCE: 4

\begin{abstract}
SUMMARY
Background. This case-control study investigated arm recovery from surgery for a ruptured distal tendon in terms of maximal strength, power, and endurance compared to the healthy contralateral arm, taking into account limb dominance.

Methods. An S-shaped single incision and suture anchor repair was used in all 15 patients. All patients were right-arm dominant and of them none participated in a specific postoperative physical therapy program. Outcomes were evaluated based on range of motion and with the Disability of the Arm, Shoulder and Hand (DASH) test, Mayo Elbow Performance Index (MEPI), and Bromberg and Morrey questionnaire. Muscle function was assessed with MuscleLab.

Results. Average test scores were as follows: DASH, 3.53/100; MEPI, 93/100; and Bromberg and Morrey, 90.87/100. There were significant differences in supination (P $=0.007)$, maximum lifted weight $(P=0.005763)$, strength during endurance exercise $(\mathrm{P}=0.004366)$, and maximum strength in flexion $(\mathrm{P}=0.045584)$ between impaired and healthy arms.

Conclusions. Limb dominance is not a critical issue for the choice of treatment and functional evaluation following surgical repair of ruptured distal tendon.
\end{abstract}

\section{KEY WORDS}

Distal biceps; bandedness; outcomes; surgery; surgical repair.

\section{BACKGROUND}

Most biceps tendon ruptures involve the proximal long head or, more infrequently, the short head; $3 \%$ of biceps injuries involve the distal insertion $(1,2)$. Males between the ages of 30 and 60 years account for $95 \%$ of cases, and the prevalence is between 0.9 and 1.8 per 100,000 patients per year $(1,2)$. Additionally, $60 \%$ to $86 \%$ of injuries involve the dominant arm, which is more debilitating for patients $(2,3)$. Biceps injuries are caused by hypovascularization in the tendon, which results in ipoxia and changes in tendon impingement on radial bone during pronosupination $(2,3)$. Other predisposing factors include high body mass index, tendinosis, osteophytes from mechanical overuse, prolonged steroid therapy, meta- bolic acidosis, smoking, and chronic inflammatory diseases (e.g., rheumatoid arthritis) $(2,3)$. Athletes who play contact sports are also prone to distal biceps tendon injuries (3).

The increasing tendency of people of all ages to engage in sporting activities has led to increased rates of injury, prompting advances in surgical practices in the field of orthopedics to achieve better outcomes including more rapid restoration of function. In fact, conservative treatment of distal biceps ruptures can result in chronic pain, reduced grip strength, and weakness of flexion and supination (3-6).

Distal biceps tendon ruptures are relatively uncommon in clinical practice and there is no consensus regarding the optimal treatment and rehabilitation program, although surgery is 
the preferred intervention for this type of injury; the literature on this topic is mostly limited to case series $(3,5-8)$. Surgery to repair distal tendon ruptures is traditionally performed through a single anterior incision or double incision. In addition to different surgical approaches, various methods and tools are used for reattachment including suturing through bone tunnels, suspensory fixation devices, suture anchors, and interference screws. While surgical reinsertion of the distal biceps tendon has good outcomes in terms of restoring strength and range of motion, complications are not uncommon $(3-5,7,9)$. Although there have been studies comparing different surgical techniques, there are no clear guidelines regarding the optimal approach for reducing complications and achieving good clinical outcomes $(3,4,7-9)$. Only a few studies have reported functional outcomes comparing the dominant and nondominant arms or impaired and healthy arms (1, 6, 10-18).

In this case-control study, we evaluated the recovery of biceps brachii following surgery for distal tendon rupture in terms of maximal strength, power, and endurance compared to the healthy contralateral arm, while taking into account limb dominance.

\section{MATERIALS AND METHODS}

\section{Study subjects}

The study meets the ethical standards of the journal (19). Approval for this study was obtained from the local bioethics committee (study no. 062951891, protocol no. 21883).

We retrospectively evaluated 15 male patients who underwent surgery to repair unilateral rupture of the distal biceps brachii tendon between January 2015 and December 2017. A single surgeon performed all of the surgeries using the same technique, which involved tendon reinsertion into the radial tuberosity with 1 or 2 suture anchors through a single $\mathrm{S}$-shaped incision using an anterior elbow approach. With the arm in maximum supination, the suture anchors were placed into the tuberosity and the torn tendon was reapproximated to the anchors. In most cases, 2 anchors loaded with sutures were used $(20,21)$. The study participants were aged between 31 and 65 years (mean: 48 years). Seven patients had a left rupture and 8 had a right rupture. All patients were male and right-arm dominant. The time from the traumatic event to surgery ranged between 2 and 15 days (mean: 5 days), and the time from surgery to follow-up was between 28 and 54 months (mean: 42.6 months) (table I). After surgery, none of the patients engaged in a specific physical therapy program for the recovery of range of motion, strength, power, and muscular endurance.

The participants were informed in detail of the scope and procedures of the study before being asked to take part in clinical evaluation, and provided written, informed consent prior to participating in accordance with National Health Council Resolution No. 196/96 and the 1975 Helsinki Declaration, as revised in 2000.

Table I. Baseline demographic and clinical characteristics of patients.

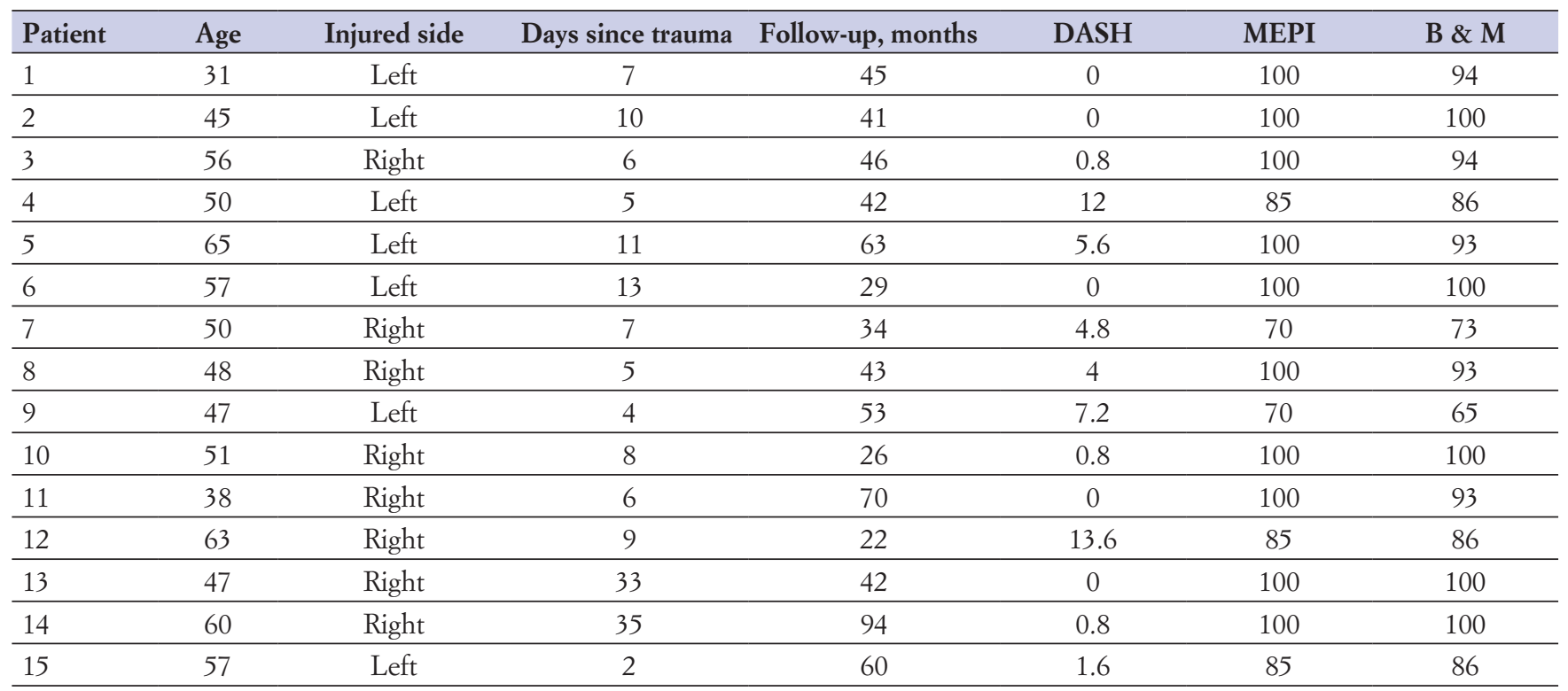

B \& M: Bromberg and Morrey; DASH: Disability of the Arm, Shoulder and Hand; MEPI: Mayo Elbow Performance Index. 


\section{Outcome measures}

Patients completed questionnaires that examined different aspects of upper limb functioning including the Disability of the Arm, Shoulder and Hand (DASH) test and Bromberg and Morrey $(B \& M)$ rating scale, which evaluated upper limb disability; and Mayo Elbow Performance Index (MEPI), which assessed limitations in daily life activities caused by impaired elbow function.

The patients were also evaluated with physical/functional tests. The MuscleLab system (Ergotest Technology, Langesund, Norway) was used to measure muscle isotonic strength, speed of motion, and muscular power with a linear encoder during elbow flexion-extension of the right and left limbs against resistance. The theoretical maximum weight lifted by each upper limb of each participant was calculated using the following equation (22):

Theoretical maximum weight $=$ weight lifted / (1.0278 $0.0278 \times$ no. of repetitions).

This equation is reliable for a number of repetitions $<12$. Measurements were first performed for the injured limb irrespective of whether it was the dominant one.

Submaximal and isotonic muscle endurance testing against resistance was carried out for each arm with the MuscleLab system. In the submaximal test, patients performed 3 flexion-extension repetitions at $90 \%$ of the theoretical maximum weight. In the endurance test, patients performed as many repetitions as possible in $1 \mathrm{~min}$ at $50 \%$ of the theoretical maximum weight. Participants were allowed a 10-min rest period between tests. For each arm, we also recorded the range of motion for flexion, extension, supination, and pronation of the elbow.

\section{Statistical analysis}

Data are reported as mean \pm standard deviation and were analyzed with the parametric Student's t test for paired data between impaired and healthy arms of the same subject. Statistical analyses were performed with Excel software (Microsoft, Redmond, WA, USA). $\mathrm{P}<0.05$ was considered significant.

\section{RESULTS}

\section{Clinical assessment}

The patients were divided into 2 groups according to the side of the ruptured biceps tendon (left, $\mathrm{n}=7$; right, $\mathrm{n}=$ 8). Baseline demographic and clinical characteristics of the participants including age, time from trauma to surgery, time from surgery to follow-up, outcome scores, and functional test results/scores were normally distributed (table II).

In terms of clinical outcomes, $5 / 15$ patients reported bearable pain near the brachiradial muscle. Average scores for the clinical assessment scales were as follows: DASH: 3.53/100; MEPI: 93/100; and B\&M: 90.87/100. There were no statistically significant differences between the 2 groups (table I). None of the patients reported functional limitations in daily life activities, and were eventually able to return to work and engage in sports.

\section{Functional assessment}

We compared functional parameters between the operated (injured) and non-operated (healthy) arms. There were no differences in flexion and extension, but average supination was $80.8^{\circ}$ in the impaired arm vs $87^{\circ}$ in the healthy arm $(\mathrm{P}=$ $0.007)$, and average pronation was $79.73^{\circ}$ vs $86.66^{\circ}(\mathrm{P}=0.02)$

(table III). The theoretical maximum weight lifted, maximum strength and power during endurance exercises, and average strength and power during submaximal tests were measured. Prior to statistical analysis of MuscleLab functional performance data, we subtracted $10 \%$ from the values of the dominant right arm to normalize the data for the 2 arms. The average maximum weight lifted with the impaired arm was $13.37 \mathrm{~kg}$ as compared to $14.52 \mathrm{~kg}$ with the healthy arm $(\mathrm{P}=0.005763)$; the average strength during endurance exercise was $64.77 \%$ in the impaired arm and $70.34 \%$ in the healthy arm $(\mathrm{P}=0.004366)$; and the maximum strength in flexion was $150.04 \%$ and $161.82 \%$, respectively $(\mathrm{P}=0.045584)$. There were no significant differences in power expressed during the submaximal test and endurance exercise between arms (table IV).

Table II. Statistical parameters for patients' baseline demographic and clinical characteristics.

\begin{tabular}{lllllll}
\hline & Age & Months since rupture & Days since trauma & DASH & MEPI & B \& M \\
\hline Avg left & 50.28571 & 47.57142857 & 7.428571429 & 3.7714287 & 91.4285714 & 89.14285714 \\
\hline Avg right & 51.625 & 47.125 & 13.625 & 3.1 & 94.375 & 92.375 \\
\hline SD left & 10.93487 & 11.88636674 & 4.035556255 & 4.65822365 & 11.8019369 & 12.088956 \\
\hline SD right & 17.39301 & 25.32949532 & 11.1428228 & 47.8507523 & 9.9389805 & 23.25430068 \\
\hline P value & 0.793726 & 0.963724582 & 0.223680698 & 0.78418795 & 0.62935914 & 0.576004703 \\
\hline
\end{tabular}

Avg: average; B \& M: Bromberg and Morrey; DASH: Disability of the Arm, Shoulder and Hand; MEPI: Mayo Elbow Performance Index; SD: standard deviation. 
Table III. Range of motion in injured vs healthy limb.

\begin{tabular}{|c|c|c|c|c|c|c|c|c|}
\hline & \multicolumn{2}{|c|}{ Supination } & \multicolumn{2}{|l|}{ Flexion } & \multicolumn{2}{|l|}{ Extension } & \multicolumn{2}{|l|}{ Pronation } \\
\hline & $\mathrm{IL}$ & $\mathrm{HL}$ & IL & $\mathrm{HL}$ & IL & $\mathrm{HL}$ & IL & $\mathrm{HL}$ \\
\hline Average & $80.8^{\circ}$ & $87^{\circ}$ & $133.6667^{\circ}$ & $136.3333^{\circ}$ & $-2^{\circ}$ & $-0.333333^{\circ}$ & $79.73333^{\circ}$ & $86.66667^{\circ}$ \\
\hline P value & 0.0075 & & 0.164318 & & 0.237666 & & 0.023208 & \\
\hline
\end{tabular}

HL: healthy limb; IL: injured limb.

Table IV. Strength evaluation in healthy and injured limbs.

\begin{tabular}{|c|c|c|c|c|c|c|c|c|c|c|}
\hline & \multicolumn{2}{|c|}{$\begin{array}{l}\text { Maximum } \\
\text { lifted weight, } \\
\mathrm{kg}\end{array}$} & \multicolumn{2}{|c|}{$\begin{array}{l}\text { STR during EE, } \\
\mathrm{kg}\end{array}$} & \multicolumn{2}{|c|}{$\begin{array}{l}P \text { during } E E \text {, } \\
\%\end{array}$} & \multicolumn{2}{|c|}{$\begin{array}{l}\text { Maximum FL STR, } \\
\text { kg }\end{array}$} & \multicolumn{2}{|c|}{$\begin{array}{l}P \text { during submaximal } \\
\text { test, } \%\end{array}$} \\
\hline & IL & $\mathrm{HL}$ & $\mathrm{IL}$ & $\mathrm{HL}$ & IL & $\mathrm{HL}$ & $\mathrm{IL}$ & $\mathrm{HL}$ & IL & $\mathrm{HL}$ \\
\hline Average & 13.37333 & 14.52 & 64.77747 & 70.34713 & -0.00847 & -0.06276 & 150.0473 & 161.8267 & 117.9283 & 120.0785 \\
\hline $\mathrm{P}$ value & 0.005763 & & 0.004366 & & 0.707989 & & 0.045584 & & 0.758272 & \\
\hline
\end{tabular}

EE: endurance exercise; FL: flexion; HL: healthy limb; IL: injured limb; STR: strength.

\section{DISCUSSION}

This study evaluated clinical and functional outcomes following anatomic reinsertion of distal biceps tendon with an S-shaped single incision using anchors. Objective measures such as recovery of submaximal muscular strength, endurance, and range of motion along with subjective patient-reported outcome were evaluated. We also compared the results for dominant and nondominant limbs.

The surgical technique used in our study yielded good results in all patients in terms of recovery of functionality and autonomy in daily life, as assessed using clinical outcome measures. We compared our results to those of case control studies that used comparable surgical technique and materials and methods (table $\mathbf{V}$ ) and found that our clinical results and subjective patient-reported outcomes substantially overlapped with the findings of most of these studies. However, isokinetic assessment outcomes in these (23-29) as well as our own study were inconsistent, which may be attributable to the various assessment tools and testing protocols used and different isokinetic parameters that were evaluated, precluding direct comparisons.

Only 5 of the previous studies considered the issue of limb dominance when analyzing the results $(9,15,18,23$, 29) (table V), with conflicting conclusions. We therefore compared all case-control studies that analyzed this factor regardless of the surgical approach, type of tendon fixation, evaluation method, average follow-up time, and sample size (table VI) and found that they yielded variable findings regarding the issue of dominance.

Isokinetic analyses are known to be affected by limb dominance (30); however, the ratio of strength and endur- ance during flexion, extension, pronation, and supination between dominant and nondominant elbows is still debated (31). It has been suggested that the contralateral upper extremity can be used as a matched control in the evaluation of postoperative strength and endurance in biceps isokinetic testing, without adjusting the results for handedness (13). According to these indications, some studies assessing the contribution of limb dominance to surgical outcome ( 9 , $14,18,23)$ did not normalize this ratio, since the strength difference favoring the dominant limb in isokinetic tests is in any case negligible. On the other hand, other studies (1, $6,10,11,15,16,17)$ corrected for this factor using various methods (15).

All patients in our study were right-arm-dominant. Functional evaluation was performed with an isotonic strength test, and we subtracted $10 \%$ from right arm values to normalize data for the 2 arms according to Peterson et al. (32). This is based on the assumption that grip strength is an objective measure of upper extremity performance (33); it was shown that grip strength of the dominant hand was $10 \%$ greater than that of the nondominant hand, although this was only true in the case of right-arm dominance. Therefore, the $10 \%$ rule is recommended for right-handed subjects, and the arms should be considered as having equal strength for left-handed subjects (32). This is partly supported by the findings of Gallagher et al. (34), who showed that for the elbow, dominance does not affect extension, pronation, or supination but significantly influences flexion in terms of mean peak torque, work, and power. In our analysis, we considered only flexion in isokinetic tests: by normalizing the results for the 2 arms, we circumvented the issue 


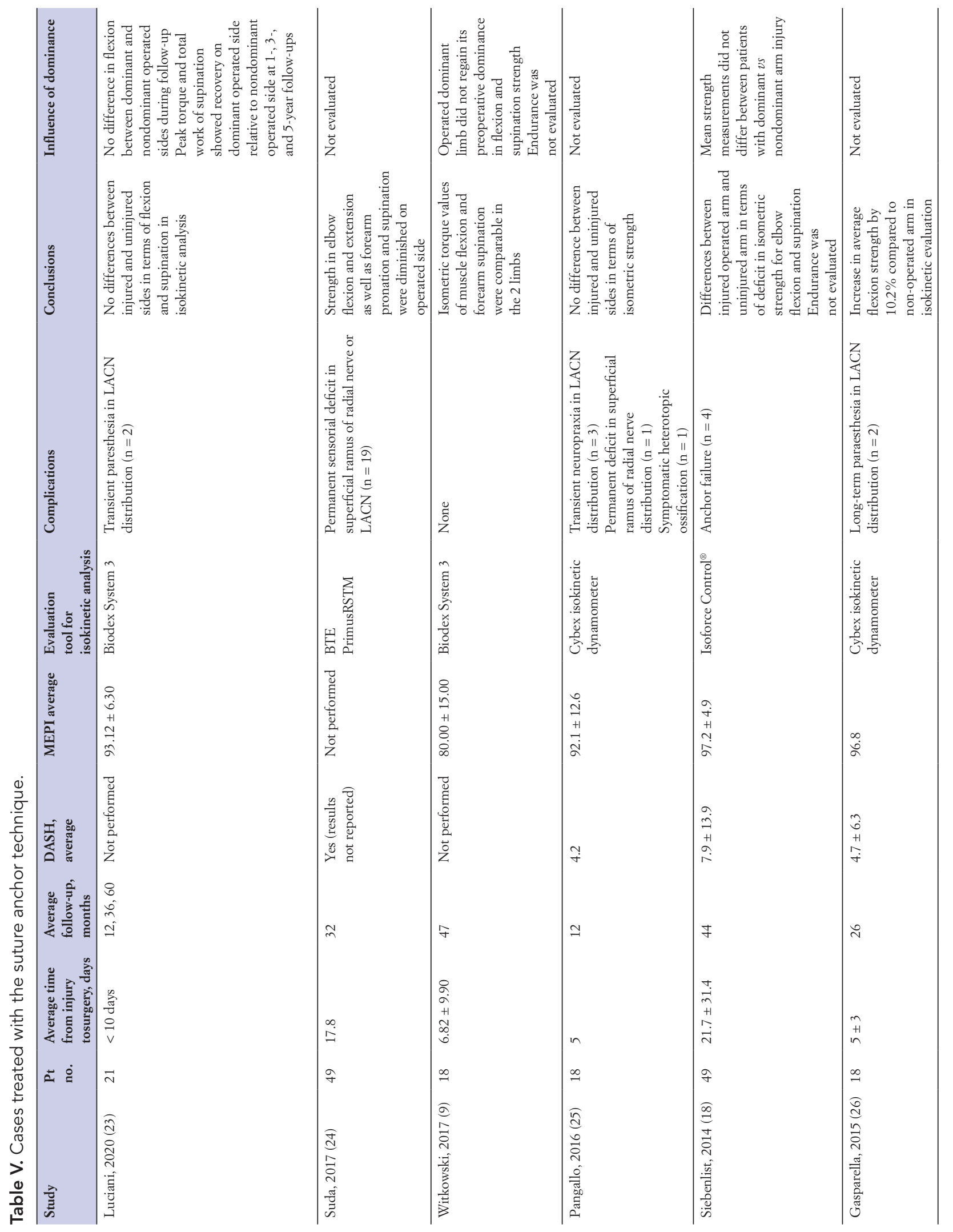




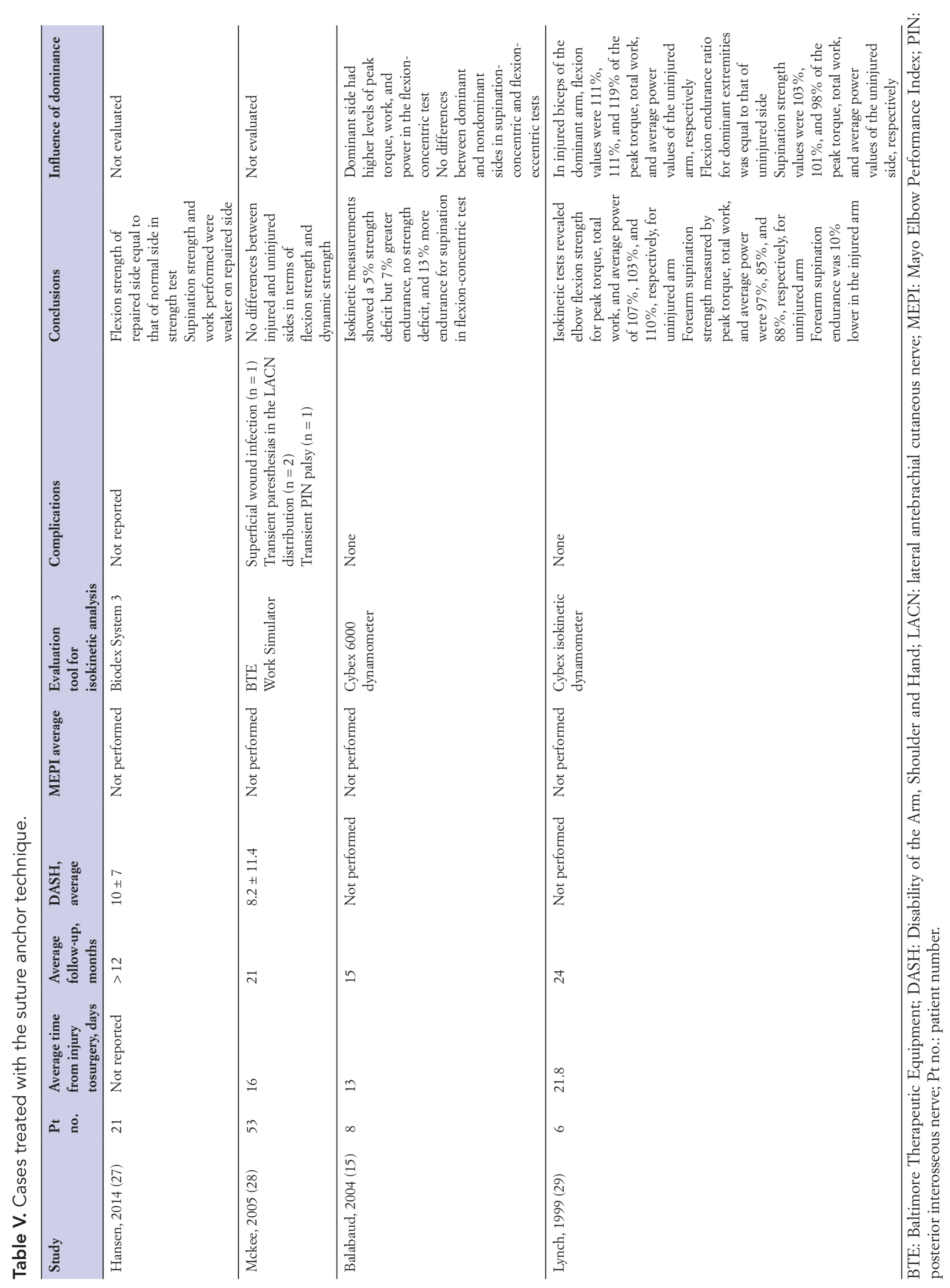




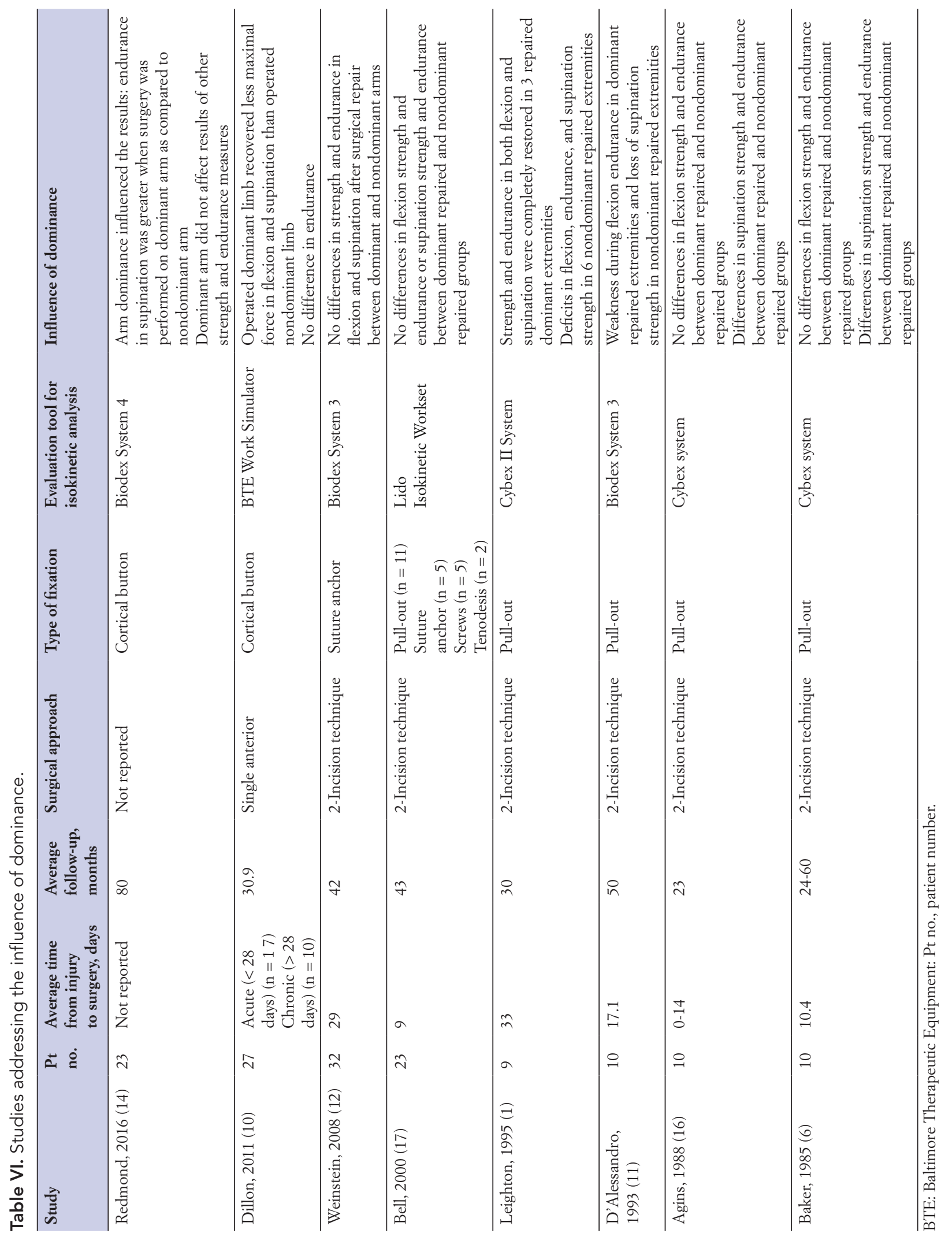


of dominance $v s$ non-dominance for isotonic flexion muscle strength; additionally, we used the healthy contralateral arm as a matched control for the injured arm in each patient. We found that the healthy limb was superior in terms of maximum lifting weight, strength expressed during endurance exercise, and maximum strength during flexion; the impaired limb had less strength and lifted a lower weight. Muscle power during endurance and submaximal exercises was comparable; that is, while the impaired limb lacked explosive strength, muscle power during the endurance test was normal and adequate (table III).

Our study had 3 major limitations. Firstly, the small sample size and study design did not allow us to draw broad conclusions, especially regarding the application of the modified $10 \%$ rule. Secondly, we did not perform a detailed analysis of supination in terms of maximum strength and submaximal and endurance testing. Even after biceps tendon repair, a persistent loss of supination strength and range of motion are expected in both dominant and nondominant injured limbs $(10,12,17$, $18,24,27,29)$. However, loss of supination strength and arc of motion in operated patients do not necessarily impact satisfaction scores, daily activities, or return to previous work $(1,10$, $11,12,14,17,23,24,29)$. On the other hand, the considerable loss of supination strength (between $21 \%$ and $55 \%$ ), endurance (up to $79 \%$ ), and supination range of motion in injured biceps tendons that have not been surgically treated has been linked to lower satisfaction scores and can impede resumption of daily activities and work; this is true for both dominant and nondominant limbs $(7,35)$ and largely justifies surgical intervention in most cases. A third limitation of our study was the

\section{REFERENCES}

1. Leighton MM, Bush-Joseph CA, Bach BR. Distal biceps brachii repair. Results in dominant and nondominant extremities. Clin Orthop Relat Res 1995;317:114-21.

2. Kelly MP, Perkinson SG, Ablove RH, Tueting JL. Distal biceps tendon ruptures: An epidemiological analysis using a large population database. Am J Sports Med 2015;43:2012-7.

3. Savin DD, Watson J, Youderian AR, et al. Surgical management of acute distal biceps tendon ruptures. J Bone Joint Surg Am 2017;99:785-96.

4. Dunphy TR, Hudson J, Batech M, Acevedo DC, Mirzayan R. Surgical treatment of distal biceps tendon ruptures: An analysis of complications in 784 surgical repairs. Am J Sports Med 2017;45:3020-9.

5. Kodde IF, Baerveldt RC, Mulder PG, Eygendaal D, van den Bekerom MP. Refixation techniques and approaches for distal biceps tendon ruptures: A systematic review of clinical studies. J Shoulder Elb Surg 2016;25:e29-e37.

6. Baker BE, Bierwagen D. Rupture of the distal tendon of the biceps brachii. Operative versus non-operative treatment. J Bone Joint Surg Am 1985;67:414-7. lack of a unified, comprehensive, and fully supervised postoperative physiotherapy program. Indeed, none of our patients followed a specific rehabilitation program after surgery, which may have biased our results. On the other hand, the good outcomes that were achieved highlight the value and effectiveness of the surgical technique.

A strength of our study was the normalization of isokinetic data for the 2 arms using the $10 \%$ rule, which allowed us to overcome the issue of dominance $v s$ non-dominance for isotonic flexion muscle strength; and the use of the healthy contralateral arm as a matched control, which obviated the need to test a group of normal subjects (1, $10,11,15,17)$.

\section{CONCLUSIONS}

Based on this new method of evaluating results, we conclude that limb dominance is not a critical factor in the choice of treatment for distal biceps injury at midterm follow-up. Patients should be informed of the possibilities of a persistent loss of flexion strength and limited supination range after suture anchor repair via a single-incision approach. We also recommend an appropriate postoperative rehabilitation program that includes muscle strength and endurance exercises as soon as the sutures allow to promote good recovery of supination.

\section{CONFLICT OF INTERESTS}

The authors declare that they have no conflict of interests.

7. Stoll LE, Huang JI. Surgical treatment of distal biceps ruptures. Orthop Clin North Am 2016;47:189-205.

8. Miyamoto RG, Elser F, Millett PJ. Distal biceps tendon injuries. J Bone Joint Surg Am 2010;92:2128-38.

9. Witkowski J, Królikowska A, Czamara A, Reichert P. Retrospective evaluation of surgical anatomical repair of distal biceps brachii tendon rupture using suture anchor fixation. Med Sci Monit 2017;23:4961-72.

10. Dillon MT, Bollier MJ, King JC. Repair of acute and chronic distal biceps tendon ruptures using the EndoButton. Hand (NY) 2011;6:39-46.

11. D'Alessandro DF, Shields CL Jr, Tibone JE, Chandler RW. Repair of distal biceps tendon ruptures in athletes. Am J Sports Med 1993;21:114-9.

12. Weinstein DM, Ciccone WJ 2nd, Buckler MC, Balthrop PM, Busey TD, Elias JJ. Elbow function after repair of the distal biceps brachii tendon with a two-incision approach. J Shoulder Elbow Surg 2008;17:82S-86S.

13. Wittstein J, Queen R, Abbey A, Moorman CT $3^{\text {rd }}$. Isokinetic testing of biceps strength and endurance in dominant versus 
nondominant upper extremities. J Shoulder Elbow Surg 2010;19:874-7.

14. Redmond CL, Morris T, Otto C, et al. Functional outcomes after distal biceps brachii repair: A case series. Int J Sports Phys Ther 2016;11:962-70.

15. Balabaud L, Ruiz C, Nonnenmacher J, Seynaeve P, Kehr P, Rapp E. Repair of distal biceps tendon ruptures using a suture anchor and an anterior approach. J Hand Surg Br 2004;29:178-82.

16. Agins HJ, Chess JL, Hoekstra DV, Teitge RA. Rupture of the distal insertion of the biceps brachii tendon. Clin Orthop Relat Res 1988;234:34-8.

17. Bell RH, Wiley WB, Noble JS, Kuczynski DJ. Repair of distal biceps brachii tendon ruptures. J Shoulder Elbow Surg 2000;9:223-6

18. Siebenlist S, Fischer SC, Sandmann GH, et al. The functional outcome of forty-nine single-incision suture anchor repairs for distal biceps tendon ruptures at the elbow. Int Orthop 2014;38:873-9.

19. Padulo J, Oliva F, Frizziero A, Maffulli N. Muscles, Ligaments and Tendons Journal - Basic principles and recommendations in clinical and field Science Research: 2018 update. Muscles Ligaments Tendons J 2018;8(3):305-7.

20. Barnes SJ, Coleman SG, Gilpin D. Repair of avulsed insertion of biceps. A new technique in four cases. J Bone Joint Surg Br 1993;75:938-9.

21. Lintner S, Fischer T. Repair of the distal biceps tendon using suture anchors and an anterior approach. Clin Orthop Relat Res 1996;322:116-9.

22. Brzycki M. Strength testing-predicting a one-rep max from reps-to-fatigue. JOPERD 1993;64:88-90.

23. Luciani P, Farinelli L, Senigagliesi E, Setaro N, Manzotti S, Gigante A. Suture anchor reinsertions of distal biceps rupture: A histological analysis of torn tendon and clinical results at short- and long-term follow up. J Shoulder Elbow Surg 2021;30(2):352-8.

24. Suda AJ, Prajitno J, Grützner PA, Tinelli M. Good isometric and isokinetic power restoration after distal biceps tendon repair with anchors. Arch Orthop Trauma Surg 2017;137:939-44.
25. Pangallo L, Valore A, Padovani L, et al. Mini-open incision for distal biceps repair by suture anchors: follow-up of eighteen patients. Musculoskelet Surg 2016;100:19-23.

26. Gasparella A, Katusic D, Perissinotto A, Miti A. Repair of distal biceps tendon acute ruptures with two suture anchors and anterior mini-open single incision technique: Clinical follow-up and isokinetic evaluation. Musculoskelet Surg 2015;99:19-25.

27. Hansen G, Smith A, Pollock JW, et al. Anatomic repair of the distal biceps tendon cannot be consistently performed through a classic single-incision suture anchor technique. J Shoulder Elbow Surg 2014;23:1898-904.

28. McKee MD, Hirji R, Schemitsch EH, Wild LM, Waddell JP. Patient-oriented functional outcome after repair of distal biceps tendon ruptures using a single-incision technique. J Shoulder Elbow Surg 2005;14:302-306.

29. Lynch SA, Beard DM, Renström PA. Repair of distal biceps tendon rupture with suture anchors. Knee Surg Sports Traumatol Arthrosc 1999;7:125-131.

30. Askew LJ, An KN, Morrey BF, Chao EY. Isometric elbow strength in normal individuals. Clin Orthop Relat Res $1987 ;(222): 261-6$

31. Kotte SHP, Viveen J, Koenraadt KLM, The B, Eygendaal D. Normative values of isometric elbow strength in healthy adults: A systematic review. Shoulder Elbow 2018;10:207-15.

32. Petersen P, Petrick M, Connor H, Conklin D. Grip strength and hand dominance: Challenging the $10 \%$ rule. Am J Occup Ther 1989;43:444-7.

33. Gilbert J, Knowlton R. Simple method to determine sincerity of effort during a maximal isometric test of grip strength. Am J Phys Med 1983;62:135-44.

34. Gallagher MA, Cuomo F, Polonsky L, Berliner K, Zuckerman JD. Effects of age, testing speed, and arm dominance on isokinetic strength of the elbow. J Shoulder Elbow Surg 1997;6:340-6.

35. Schmidt CC, Brown BT, Sawardeker PJ, DeGravelle M Jr, Miller MC. Factors affecting supination strength after a distal biceps rupture. J Shoulder Elbow Surg 2014;23:68-75. 